Article

\title{
Scientific Support for Redesigning a Higher-Education Curriculum on Sustainability
}

\author{
Corinne Ruesch Schweizer*, Antonietta Di Giulio and Patricia Burkhardt-Holm \\ Program Man-Society-Environment (MGU), University of Basel, Vesalgasse 1, CH-4051 Basel, Switzerland; \\ antonietta.digiulio@unibas.ch (A.D.G.); patricia.holm@unibas.ch (P.B.-H.) \\ * Correspondence: corinne.ruesch@unibas.ch
}

Received: 27 June 2019; Accepted: 28 October 2019; Published: 30 October 2019

\begin{abstract}
This paper is devoted to how a team of experts scientifically supported redesigning the curriculum of an elective study program that promotes competences for sustainable development. In contrast to other case studies of higher education for sustainable development (HESD), the paper does not present the outcome of the curricular-redesign process but focuses on its scientific support. It shows how this process was initiated and facilitated. It understands curricular redesign as a social process. The premises are, first, that supporting curricular processes means guiding the decision-making of those in charge but not making decisions in their place, and second, that the redesign of a curriculum has to consider the existing institutional situation as well as empirical and theoretical expectations. The article discusses how scientific support can help a curricular redesign draw on both experience-based knowledge and sound HESD theories and findings. Furthermore, it reflects on the role of those supporting such a process and on how they can help the actors find a realistic compromise between the existing situation and the perceived ideal. This requires competences in mining, aggregating, and reprocessing knowledge in the field of HESD, as well as in designing and supporting an interdisciplinary process.
\end{abstract}

Keywords: higher education for sustainable development; curriculum development; interdisciplinary processes

\section{Introduction}

There is a broad consensus that universities should promote competences for sustainable development [1]. Accordingly, an increasing number of higher-education institutions (HEIs) are implementing higher education for sustainable development (HESD) by integrating sustainable development as a perspective into existing disciplinary degree programs (e.g., [2,3]) by offering specialized degree programs or minors on sustainable development (e.g., [4]), or by providing elective study programs in which students can acquire competences for sustainable development in addition to their disciplinary degree program. In German-speaking countries, students are, as a rule, given the possibility of adding to their studies by choosing an elective study program from a broad range of offerings (in German this is called, for example, "freier Kreditpunktbereich" or "Studium Generale"). The amount of credit points students have at their disposal for such programs varies across universities, and so the size of such elective programs varies in terms of credit points as well [5].

HESD discourse provides a number of conceptual approaches to the question of which competences and learning outcomes should be attained in sustainability study programs (e.g., [6-13]), and it provides an extensive discussion about the pedagogical methods that support the acquisition of these competences (e.g., [14-17]) as well as about the structural factors of implementing such programs at HEIs [3,18-20]. The practical and yet unresolved challenge is how to use these approaches in designing study programs (e.g., $[12,21])$. This challenge is caused by the fact that "there are no two 
institutions alike and within institutions, no two schools alike" [22] (p. 9). Furthermore, within HESD discourse, scholars adopt different definitions of sustainable development, leading to different criteria for designing study programs (e.g., [22-24]). Depending on which definition and criteria a program selects, a different competence approach is chosen [25]. In designing elective study programs, two additional points have to be considered. First, the group of students is interdisciplinary, so the content presented and the questions discussed in these study programs have to link to a number of disciplinary perspectives, which may, in contrast to other types of curricula, change from one year to the next depending on the cohort of students. Second, compared to degree programs on sustainability, the number of hours and courses in which teachers interact with students in these programs is rather small. HESD discourse does not provide approaches or procedures that offer practical support for such challenges. Quite a number of universities have been offering elective study programs for many years now, and this has led to a considerable amount of case studies describing these programs (e.g., $[4,26,27])$. Most of these case studies focus, however, on the results of the design process rather than on the process itself. Yet, describing and reflecting on the learning processes that are part of the curricular-redesign process is necessary to understand the factors that initiate, ease, support, or impair such curricular learning processes. The fact that this process is such a blind spot in the debate is quite remarkable, all the more so considering how HESD discourse emphasizes that continuous curricular learning processes are central to implementing HESD (e.g., [2,28]).

This article addresses this blind spot. We focus on the processes that lead to a curriculum, and more precisely, on the social processes, which we consider to be necessary to designing and revising curricula in elective study programs. Instead of addressing the overriding structural difficulties or key factors of implementing HESD (e.g., [20,28,29]), we solely focus on the process of improving the content and didactics of such curricula (subsequently referred to as the curricular-redesign process). We thus focus our attention on the quality development of HESD curricula. Quality development is addressed in HESD discourse with design proposals (e.g., [8]), and it is one of the topics discussed in the debate about professional development for HESD educators (e.g., [21]). The third important element for quality development is context-specific improvement of HESD curricula. The process of such context-specific quality development is the subject of this article.

We report and critically reflect on a curricular-redesign process we have supported and accompanied as scholars in the sense of an HESD-specific learning and improvement process. This paper is a theory-based and data-supported reflection on this process and can thus best be characterized as action research rather than as a case study in a strict sense. Following the rationale of action research, the paper describes the iterative shift between research (i.e., surveys, analysis, evaluation) and development (i.e., deciding on action consequences) $[30,31]$ in the curricular-redesign process of a study program.

The study program is the Transfaculty Cross-Section Program on Sustainable Development (TQNE) at the University of Basel, offered as an elective program and open to all students (bachelor's and master's). It started as a minor subject in 1992. In the context of the Bologna reform, it was transformed into a transfaculty cross-sectional program requiring 12 credit points. A second redesign-which we will report on in this paper-was undertaken and scientifically accompanied in the frame of the project "Sustainable Development on Bachelor Level—An Immersive Programme in Sustainable Development." It was funded as part of the Sustainable Development at Universities Programme (2013-2016) of the Swiss Academies of Arts and Sciences and the Network for Transdisciplinary Research (td-net). One of the goals of this program was to fund projects aimed at developing or further developing study programs. It thus provided an opportunity and the necessary resources to evaluate and improve TQNE based on sound evidence about students' and teachers' experiences and needs. The redesign followed a transdisciplinary approach; that is, both certified experts (with scholarly expertise in HESD) and uncertified experts (with experience-based expertise in HESD) were involved in a collaborative process [1,32]. The project team was structured as follows: (a) a redesign team made all the decisions, and this team consisted of two delegates total from the three faculties responsible 
for TQNE (Faculty of Science, Faculty of Humanities and Social Sciences, Faculty of Business and Economics) and the coordinator and two main lecturers from TQNE; (b) a support team provided scientific support, and this team consisted of two HESD experts who were not involved in the original design nor in implementing or delivering TQNE. To ensure the integration of knowledge, a close collaboration was established between the head of the redesign team (one of the delegates from the faculties) and the support team. These three persons are the authors of this paper.

The scientific support provided by the support team consisted of three elements: (1) generating data to serve as a basis for curricular and didactic decisions; (2) advising the redesign team in decisions about changing the study program and about how to communicate the program to students; and (3) evaluating the pilot courses of the redesigned study program. These elements cover what is generally recommended in curricular-redesign processes [33-36]. The third element, evaluating the pilot courses, not only served the function of supporting further improvements, but, at the same time, made it possible to evaluate the redesign process including the scientific support. The main tools developed and used in the supporting process were: (1) a briefing note targeting the meso level, that is, a document listing what had to be decided to redesign the study program, delineating promising alternatives with regard to these decisions, and providing knowledge about these alternatives; (2) a workshop targeting the micro level, that is, a workshop aimed at broadening the lecturers' knowledge of methods that could be used in the design and delivery of single interdisciplinary teaching units.

The aim of this article is to present and discuss a promising approach to redesigning HESD study programs, especially with regard to how a scientific support team can temporarily facilitate and complement those in charge of delivering the program. In describing and discussing such a scientifically supported redesign, this paper gives attention to the learning process in program redesign and to what it means to support such a process. The paper is structured as follows:

In Section 2, we report on the institutional situation of TQNE. The considerations that led to the design of the scientific support are outlined in Section 3. Section 4 describes the quantitative and qualitative data analysis that the scientific support was based on. The main tools developed for the scientific support are delineated in Section 5. In Section 6, we present the outcome of the redesign process on the basis of the new curriculum and the formative evaluation of the pilot courses. Finally, in Section 7, we critically discuss the scientific support described in this paper and, in Section 8, draw conclusions that reach beyond the case under consideration.

\section{Point of Departure: The Institutional Situation for a Redesign}

TQNE offers courses on sustainable development as an elective program to students from all disciplines. In 2005, in the context of the Bologna Process, the existing basic program of the minor subject Man-Society-Environment was adapted to form TQNE. This revision resulted in a structure consisting of four lectures: (I) Cultural and Social Sciences, (II) Natural Sciences, (III) Reflecting on the Sciences, Concepts, and Fields of Interest in Sustainable Development, and (IV) Economics and Reflections on Sustainable Development. The courses were delivered by four lecturers from the respective disciplines, partly complemented by guest lecturers contributing their experiences and knowledge of the world beyond academia, especially with regard to sustainability in praxis. Each lecture course was accompanied by a tutorial, which especially supported students who were not familiar with the disciplinary approaches the lecture focused on. In these tutorials, advanced students acted as tutors and advised students from the current cohort. Students worked in small groups on the topic of the previous lecture by reading and analyzing texts and completing exercises. All four courses could be attended independently of each other. After completion of the overall program of 12 ECTS (4 ECTS per course), students received a certificate.

The catalyst for the redesign was the University of Basel's new strategy for the years 2014 to 2018, which envisaged establishing sustainable-development programs for teaching knowledge and critical reflection on at least one sustainability issue to students (Universitätsrat Universität Basel 2012). At the same time, there were other reasons why it was time to reflect on the future of TQNE: The broad range 
of sustainability topics collided with the small number of courses that could be offered by TQNE. TQNE could not adequately cover all aspects of sustainable development. The students, however, had high expectations: they wanted more interdisciplinarity as well as authentic contributions from different disciplines, and they wanted to be able to apply the theoretical knowledge they acquired.

The redesign project was initiated by delegates from the three faculties responsible for TQNE (Faculty of Science, Faculty of Humanities and Social Sciences, Faculty of Business and Economics). This led to their being committed to the redesign process right from the beginning. The main lecturers were willing to engage in this process because they were convinced of its necessity. This was a promising situation for a successful learning and redesign process, all the more considering that some members of the redesign team had many years of experience with the study program. However, TQNE was only a minor responsibility for all participants, so the resources in terms of time and personnel were rather limited. These structural conditions were not addressed in the redesign process but taken as a given. The redesign process thus focused on developing the curriculum design under the given conditions.

\section{Design of the Scientific Support}

In this section, we introduce the scientific support of the redesign process; this scientific support is the core of this paper. The previous section describes the existing curriculum, which had been applied successfully for many years and had already been redesigned once, so the starting points for the redesign process were a proven and previously redesigned curriculum and a sufficient number of students. The redesign process, therefore, did not focus on a theory-driven conceptual change with the goal of optimal content and an ideal didactic structure of the program from a theoretical point of view, which would have required a didactic approach to program development. Nor was the study program's suitability to students a priority of the redesign, which would have required a structure-oriented approach to program development. Rather, the aim of the curricular redesign was to optimally reflect on program directors', coordinators', lecturers', and students' experiences with the study program based on current HESD discourse and to improve the practical implementation of the curriculum. These goals brought the curriculum as a "contextualized social process" [37] (p. 89) into focus in its capacity to provide an instrument for guiding the actions of the actors involved. This led to a process-oriented approach to program development (for an overview of these three approaches to study-program development, see [38]). "According to the social curriculum model, working on the curriculum at the program level represents an ongoing social process between the actors under the given conditions. The latter refer to the organisational concept of faculties, which are characterised by the elements 'autonomy' and 'collegial consensus finding.' It is therefore relevant to working on curricula that the freedoms of the actors involved are preserved as far as possible while at the same time a framework exists that allows systematic development of the study program in the sense of goal-oriented structuring of the social processes" [37] (p. 163; translated by the authors).

For a curriculum to optimally fulfill this action-guiding function, actors must accept it as their guiding principle. According to the notion of the curriculum as a "social process," the process-oriented approach to program development emphasizes the importance of participatory work on the curriculum, of the planning process, and of the process of implementing the curriculum [38,39].

According to a process-oriented approach, the aim of supporting a curriculum redesign is not to design a curriculum on the basis of expert knowledge in such a way that it contributes to the best possible achievement of the learning objectives. Rather, the aim of scientific support should be to provide a scientifically sound framework for the participative process. This framework, in turn, should allow the redesign team to carry out systematic improvements to a curriculum that will guide their actions $[39,40]$. On this basis, we considered the following points in shaping the scientific support for the redesign process of TQNE; they are also illustrated in Figure 1. 


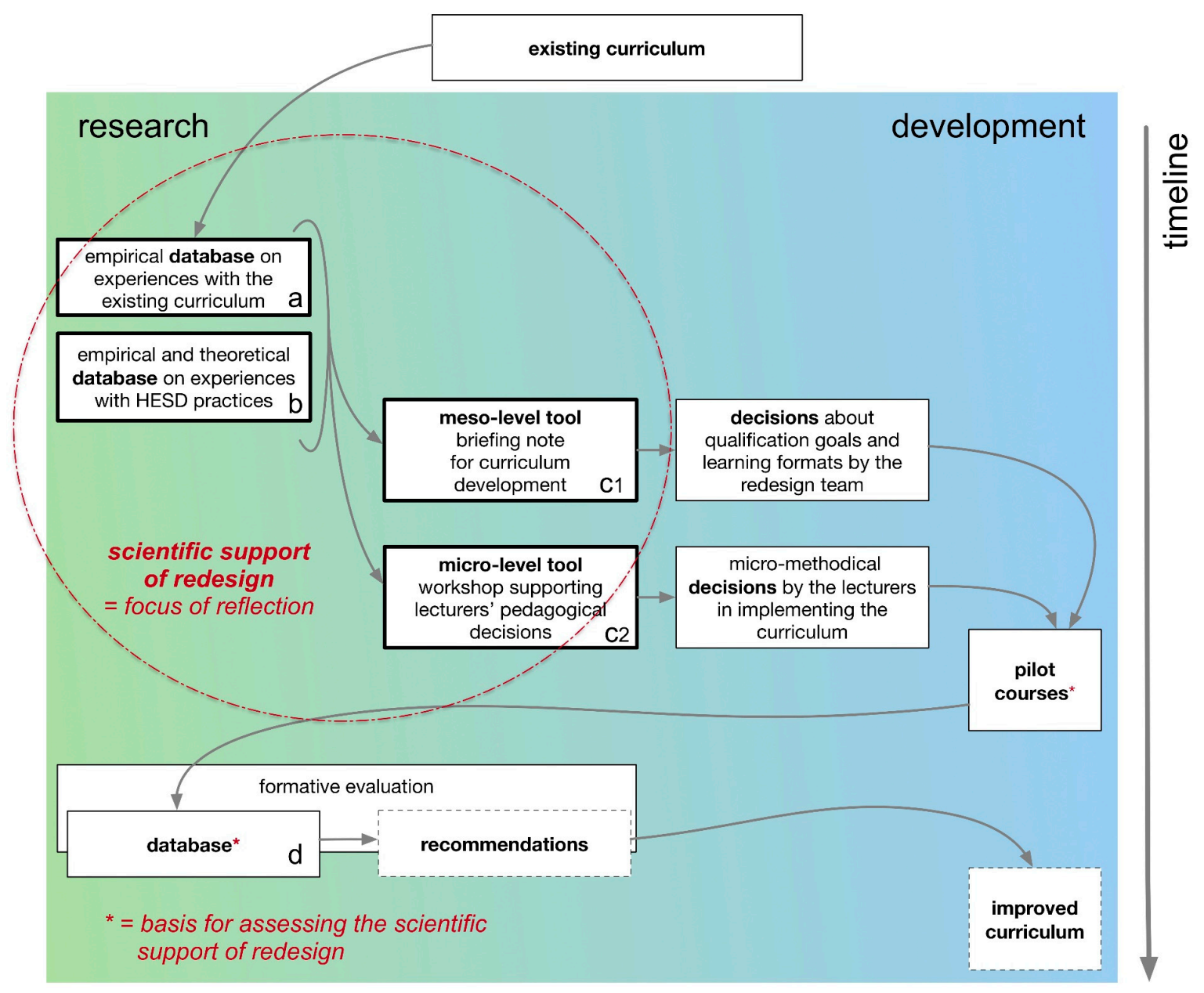

Figure 1. Curricular-redesign process shifting between research and development.

(a) Ideally, redesigns should be based on a shared understanding of previous experiences with a curriculum. However, opening a broad discussion with several lecturers, especially when they are from different faculties and institutions, entails the risk that the discussion is defined by the political interests of the participants (and their home institutions) (e.g., [41]). In this case, such a discussion would have been too time-consuming in the given time and resource frame. As a consequence, the support team decided together with the head of the redesign team to collect the various lecturers' experiences without having them develop a shared understanding of those experiences. As a result of this decision, the support team conducted a neutral survey and provided a framework for neutral analysis that collected and condensed the different experiences of those involved. This made it possible to refer to empirical data in the redesign process without feeding the data into the social-negotiation process.

(b) Considering that the redesign team and lecturers were able to draw on their different professional backgrounds when interpreting empirical data [42] but not on scholarly expertise in HESD, the support team created a basis for interpreting the data reflecting a broad diversity of HESD approaches and findings (e.g., [6-11,14,43-45]) and including actual experiences with designing and implementing HESD elective programs that are not (yet) reflected in HESD discourse. This was meant to ensure that the redesign team would not have to rely only on the approaches adopted by the members of the support team.

(c) Since the redesign team did not have scientific knowledge about curriculum development, it either had to be endowed with scholarly knowledge that would enable it to shape the curriculum-development process $[2,40]$ or it had to be guided through this process. The support team 
together with the head of the redesign team decided in favor of the latter, not least because of the time resources available to those involved.

(d) A perspective that understands curricula as guiding actions directs attention to the planning and, especially, implementation processes. The support team, therefore, undertook a formative evaluation of the pilot of the redesigned study program. The evaluation focused, first, on whether the redesigned curriculum was actually guiding the lecturers' actions in courses. Second, it focused on inviting students, who had not yet been actively represented, to assess the redesigned curriculum with regard to the challenges identified in the previous evaluations.

Points (a) and (b) led to generating databases, which are reported in Section 4. Point (c) led to developing two products that supported the redesign process. These are presented in Section 5. Finally, point (d) led to a formative evaluation of the pilot of the redesigned study program, which supported the further improvement of the study program. This evaluation also made it possible to reflect on the redesign process and the scientific support accompanying it. In Section 6, we report on the concept and the results of the evaluation with a view to this reflection.

\section{Database for the Redesign: Three Perspectives Based on Experience}

In this section, we present the methods used for generating data in points (a) and (b) described in the previous section and the resulting findings. Particular emphasis is placed on the findings that led to the development of the two main tools for supporting the redesign process.

\subsection{Study Design}

The aim of the data was to identify what elements of TQNE should be improved and how improvements could be achieved. To address the former, the study wanted to build on the experiences of students and lecturers involved in TQNE. To address the latter, comparable study programs were analyzed to explore ideas for making improvements. This brought the experiences of directors of similar study programs to the fore. The focus on the perspectives of students and of lecturers as well as on the perspective of directors of comparable study programs led to the following three steps in data generation:

Analysis of the students' course evaluations. The analysis of the students' assessments relied on data that had already been collected during the last eight years using a standardized questionnaire with questions about the individual courses (for each course, five to seven sets of course evaluations were available, with six to 90 (average: 34 ) completed questionnaires for each set). The survey questionnaire included questions on student participation, on the didactic and methodological aspects of the course, and on the performance of lecturers and tutors. These questions were answered on a five-point scale. In addition, the questionnaire included open questions, namely, what the students would suggest to improve the course, and what they liked or disliked most. The data were aggregated for each course individually. The answers to the open questions were analyzed and led to categories that were used in the subsequent empirical steps.

Semistructured interviews with previous lecturers. Nine lecturers were interviewed. The selection was made so that at least one lecturer of each of the four courses was interviewed. The assessments and experiences of the lecturers were collected in semistructured interviews that lasted about half an hour. On one hand, lecturers were asked about their own positive and negative experiences in delivering TQNE courses and what, if any, changes they would propose in the content and format. On the other hand, they were asked about the topics they chose for sustainable development, the criteria for their choice of topic, their understanding of sustainability, and the relevance of their area of expertise. The answers were summarized and the summaries analyzed. In this analysis, particular attention was paid to the points raised by students in their course evaluations.

Semistructured interviews with directors of similar study programs and document analysis of those programs. A matrix was developed as the basis for interviewing directors of similar study programs. One dimension of this matrix consisted of points raised by students in their course evaluations and of 
points raised by lectures in their interviews (diversity of topics, heterogeneity, common focus, learning activities, resonance, and number of students). The other dimension of the matrix consisted of elements particularly relevant to constructing and implementing study programs (the objectives, the formal structure, embedding the study program in the university's overall offerings, course formats and methods, content, assessment, admission requirements for students, requirements for lecturers, and communication about the study program). The support team identified questions that arose at the intersection of these two dimensions. These questions served as the basis for the interview guidelines. To prepare the individual interviews, the support team analyzed official documents on the study programs and individualized the interview guidelines accordingly. The sample for the interviews was formed on the basis of criteria that ensured that the institutional situations of the study programs were comparable to those of TQNE: study programs offered by a full university within the framework of basic teaching, integrated as a minor subject or as an elective study program consisting of at least 12 and at most 30 credit points, accessible to bachelor's students from different disciplines, taught by an interdisciplinary team of lecturers, and offered for at least three years (status 2014). The sample comprised a total of eight study programs in Germany and Switzerland. The interviews with other program directors were conducted by telephone and lasted about an hour. The transcribed interviews and documents on the study programs were subjected to computer-aided (MAXQDA) qualitative content analysis [46] based on the matrix.

\subsection{Findings for Evidence-Based Support of the Redesign Process}

The analysis of the course evaluations identified five points to be taken into account in the redesign. The students perceived these points as central to the value and quality of TQNE by expressing that they should be maintained, strengthened, or improved. The interviews with the previous lecturers identified what challenges they were facing with regard to these points, how they had dealt with them, or how they would like to deal with them. The analysis of how comparable study programs had dealt with these challenges led, on one hand, to a range of possible measures for addressing single challenges and, on the other, to insights into overarching challenges and circumstances. Instead of reporting the results of the three steps of the study individually, the following aggregates them thematically.

Diversity of topics and overview of the discourse. The students appreciated the variety of topics dealt with in TQNE and the overview it provided of sustainability discourse. However, they expressed a desire for a more transparent and comprehensible selection of topics. The lecturers, in turn, saw their thematic expertise more as a means of providing insights into fundamental questions, contexts, and approaches. There was, however, no consensus among the lecturers about what insights TQNE should provide; that is, what were the central learning objectives. Accordingly, there were no coherent reference points for selecting content. The analysis of comparable study programs did not reveal any general heuristics that all or a majority of programs had applied to select and weight the program's learning objectives. Instead, the scholarly background and corresponding positions, approaches, and theories of the program directors informed their decisions in designing the program. However, comparing the objectives and contents of the study programs revealed two overarching objectives: (1) to enable students to understand, assess, and discuss sustainability issues from a scientific point of view; and (2) to enable students to (co)design processes for coping with sustainability problems. Only a few study programs focused exclusively on one type of learning objectives; most pursued learning objectives of both types, but with different weightings (for further details, see [47]).

Interdisciplinary orientation - heterogeneity. Students thought the interdisciplinary structure of TQNE should be preserved. The lecturers emphasized the challenges that emerged from its interdisciplinary structure: dealing with the heterogeneity of the students (in discipline and number of semesters studied) and integrating the different perspectives in a way that goes beyond mere accumulation. By contrast, the interviewees from other programs perceived the disciplinary heterogeneity of their students as a potential to be used in the study program. In addition, the data showed that the study 
programs take other heterogeneities into account (aspiration to specialize, subject-related interests, existing experience).

Common focus. Students assessed a clear structure as important and complained that the connections between topics and between individual courses and the broad topic of sustainable development were not clear. In addition to lack of a common point of reference mentioned above, the lecturers also pointed out that they knew little about what the other lecturers addressed in the other courses (topics, questions, theories, etc.). The analysis of comparable study programs indicated that there is a variety of study-program structures. Programs that were more geared toward empowering students to (co)design processes for coping with sustainability problems had at least some consecutive courses. In contrast, the individual courses in programs that focused more on making students understand, assess, and discuss sustainability issues built on each other to a lesser extent or not at all. The directors of these programs tried to establish a common focus in two complementary ways: one was by coaching the lecturers; the other was by communicating the common focus to students. How strongly the lecturers participated in the common focus varied. However, the program directors who were interviewed pointed out that even if lecturers are forced to formulate concrete course objectives, the common focus can only be guaranteed to appear to a limited extent.

Active and collaborative learning. Both lecturers and students wanted more discursive and interactive learning. The other programs examined employed a wide variety of course formats including lectures, project courses, and excursions. More extensive programs had a greater variety of course formats. However, none of the study programs focused exclusively on lectures, and almost all of them incorporated more active formats that allowed more personal interaction.

Resonance and number of students. Some lecturers addressed the appropriate number of students as a topic. The data revealed a contradiction on this point between a desire for a high demand for the program and a manageable group size that allows for more intensive discussions. The directors of similar programs also assessed a high number of students as both positive and negative since it impairs mentoring of students. The data showed that while the number of students depended on the structure of the study program (the size of the courses on offer and the resources available), it also depended on factors that cannot be directly influenced (such as the study regulations for degree programs).

Interpreting the results gained in the three steps of the study with regard to the relevant literature about HESD revealed three basic factors that were pivotal for the decisions in redesigning TQNE.

First, the data showed that students and lecturers largely shared two beliefs regarding the fundamental orientation of such study programs. One relates to a stronger interlinkage of the individual courses in terms of content with a view to sustainable development. The desire for a stronger interlinkage reflected lecturers' and students' belief that sustainability goes beyond disciplinary insights and necessitates an integrated approach. This belief uncovered an area of tension between the curricular breadth desired by students and the depth of insights into fundamental (disciplinary) questions sought by lecturers. This, in turn, directed our attention to the need to strike a balance between curricular breadth and depth. Vincent and Focht [48] point to two possible orientations for a program's learning objectives, which can be combined with such a balanced-that is, a broad and selectively in-depth-curriculum: that students become environmental problem-solvers or environmental integrators. The other shared belief was in line with the didactic principles postulated for HESD [49]: all respondents emphasized active and collaborative learning as an important feature of such a study program.

Second, the data showed that different dimensions of curricular decisions are closely intertwined, including the institutional situation, the learning objectives and formats, and the number of students. Such interdependencies are not surprising since curriculum-development models reflect them. At the same time, these interdependencies draw attention to the fact that iterative decisions are required to redesign a program (e.g., [34]). With regard to the curricular and didactic decisions that had to be made in redesigning TQNE, however, it was not only important to know which dimensions interact but also 
the direction of influence in order to make it possible to consider the interplay and its consequences in decision-making.

Finally, statements by the lecturers and directors of similar study programs indicated that attention should be paid to the diversity of the disciplinary backgrounds of the program directors and lecturers involved. This diversity of disciplinary backgrounds manifested itself, for example, in different understandings of sustainability and how they were implemented in the courses. The implementation of HESD and the curricular requirements are thus highly dependent on the disciplinary profile of the lecturers involved, on the scholarly approaches they adopt, and, finally, on their time resources. In sum, this corresponds to the importance attributed to the backgrounds of individual lecturers and directors in shaping HESD at each university (e.g., [50]).

These factors are all context-sensitive, and this in turn made it impossible to find proven and generally applicable heuristics for curricular decisions. It showed that the curricular design of study programs requires coherent decisions for each specific context. This applies all the more to elective study programs that depend on students' ability to integrate them into their studies.

\section{Tools for Supporting the Redesign}

In discussing the results presented in the previous section, the head of the redesign team and the support team derived four points to address in redesigning TQNE: learning objectives and formats (meso-level decisions), methodological design of teaching units (micro-level decisions), advertising for the redesigned study program (advertising concept), and reflection after the pilot of the redesigned study program (evaluation). The two main tools developed to support the decisions at the meso and micro levels are highlighted and described in more detail in this section.

The two tools targeted complementary levels (meso level, micro level) and have complementary target groups (redesign team, lecturers delivering single courses). This approach mirrored a basic principle of the redesign process: Everyone involved in the implementation of TQNE should be involved in the decisions; that is, decisions should not only be made by the program directors (meso level) but also by those in charge of designing and delivering the single courses (micro level). Furthermore, decisions impacting the meso level and decisions impacting the micro level should be clearly distinguished; that is, lecturers delivering single courses should not participate in decisions affecting the meso level, and the redesign team should be assigned only limited competences with regard to decisions affecting the micro level. Accordingly, the program directors and the main lecturers (the redesign team) should make the decisions about the orientation and design of the program, and the other lecturers should make the decisions about the design of their individual courses. In this way, the redesign team wanted to achieve both a coherent design of the study program that integrated the courses using a common focus without prescribing too much to the individual lecturers. This division of responsibilities addressed the tension between the individual lecturers' freedom and the overall coherence of the study program.

\subsection{Providing Support for Curricular Decisions at the Meso Level (Learning Objectives and Formats)}

Decisions about learning objectives and formats required knowledge not only about sustainable development but also about curriculum development and HESD. While the members of the redesign team had disciplinary and interdisciplinary knowledge about sustainable development as well as teaching experience, they did not possess theoretical and methodological knowledge about curriculum development and HESD pedagogy. Accordingly, the support team aimed to assist them in their decisions by providing knowledge about HESD pedagogy and curriculum development.

For this purpose, the support team developed a briefing note targeting the meso level. The briefing note listed the most important things that had to be decided in redesigning the study program. It was supposed to guide the redesign team through the redesign process and allow them to draw on HESD knowledge in their decisions. It was also supposed to prevent the support team from making decisions based on its knowledge and preferred approaches instead of leaving the decisions to the 
redesign team (i.e., the technocratic trap). At the same time, it enabled the redesign team to conduct a well-founded negotiation and decision-making process. The briefing note encompassed the following complementary types of information:

Which decisions are to be made? The briefing note listed the decisions that had to be made to redesign TQNE. With regard to these decisions, the support team elaborated on the points derived from lecturers' and students' experiences with TQNE, which are presented in the previous section (i.e., decisions about the learning objectives and the selection of topics, dealing with heterogeneity, implementation of the common focus, integration of learning activities, defining the desired resonance and the appropriate number of students). As the decision points were based on the lecturers' experiences, they formed a bridge between the redesigned curriculum and existing individual experiences in TQNE.

How do others deal with similar challenges? For each decision, the briefing note also described how comparable study programs had dealt with similar challenges. This made available not only a spectrum of options but also the experiences from these study programs so that they could be used as a basis for decision-making. Here too, the intention was to build on concrete, comparable experiences and thus to make experience-based knowledge available. This knowledge was organized using categories derived from practical demands and not by categories from theoretical approaches.

What decision criteria can be applied? The briefing note offered decision criteria for each of the decisions that had to be made. These criteria explained how the different options could impact other decisions; that is, they described the consequences that had to be considered (for example, the impact of process-oriented learning objectives on the structure of the courses). In order to formulate these criteria, the support team drew on current HESD discourse and the findings from the empirical comparison of study programs. The criteria were intended to help the redesign team reflect on the design possibilities and could be used as a basis for making decisions.

How to shape the decision-making process? The aim of the briefing note was to guide the redesign team through the curriculum-development process, not only by identifying the range of decisions to be made but also by guiding them on their way through making decisions. As already stated in the previous section, the curriculum-development process is characterized by interdependent decisions and should therefore be understood as an iterative process. In order to reduce the complexity, the briefing note distinguished between two levels of decision-making. The first level concerned the general orientation of the study program, and the briefing note condensed this level into the following points: learning objectives and content orientation, structure of the study program, and learning activities. The second level addressed designing and implementing single courses and their interlinkage: dealing with heterogeneity, especially that of students but also other heterogeneities (aspiration to specialize, subject-related interests, existing experience), pedagogical formats, desired resonance, and the common focus.

\subsection{Workshop on the Micromethodological Design of Teaching Units}

The workshop targeting the micro level aimed to bridge the gap between developing the curriculum and implementing it as a guiding principle for action when lecturers deliver single courses. The workshop tried to equip all TQNE lecturers with the necessary capacities to implement the curriculum in the spirit conceived by the redesign team. Because this was not a matter of specialist knowledge in terms of content, the support team focused on linking the lecturers' expertise and pedagogical experience with HESD pedagogy.

The redesign team had decided that the primary learning format in TQNE should continue to be lectures and that active, expressive learning activities should be implemented in this format. The challenge for the lecturers would therefore be activating students on the micro level despite the rather passive format on the meso level. This decision informed the design of the workshop. The interviews with the lecturers indicated that they viewed interactive elements as very important to their lectures. Most, therefore, used micro methods. However, their statements suggested that they were not so focused on fitting the learning process to the content as on applying a certain micro method 
in and of itself, for example to give the lecture a rhythm. Accordingly, micro methods were primarily used to activate students so as to give the lecture a rhythm rather than to support learning processes.

Against this background, the aim of the workshop was, first, to raise awareness about micromethodological decisions, particularly with regard to the fact that activating students is not an end in itself but is related to the learning goals and process. Second, the workshop introduced lecturers to a number of concrete micro methods that could be employed as active, expressive learning activities and as reflective activities. The workshop had the lecturers reflect on their purposeful use in their own courses.

Proceeding from the assumption that learning objectives, teaching methods, and content are interdependent (interdependence hypothesis [51]), the aims were to build a capacity to navigate through the existing methods as well as to provide the lecturers with criteria for selecting methods or perhaps even for developing their own methods to fit their content and objectives.

This led to the following structure for the workshop: An exemplary implementation of a micro method was used to reflect on the consequences of promoting active and expressive learning activities by shifting the emphasis from providing information to developing skills and from teaching content to activating and reflecting on students' beliefs. Then, with a view to different levels of active, expressive learning activities, the workshop collected the lecturers' experiences with different methods and presented further examples (concept maps, debates, role-playing, simulations, etc.). Finally, using the theory of teaching choreographies [52], the workshop reflected on how to select micro methods by imagining students' learning processes.

\section{Redesigned Curriculum and Results of Formative Evaluation}

This section reports the results of the evaluation. We focus on the results that allow for a critical reflection on the redesign process and its scientific support. First, we describe what has been revised in the TQNE curriculum. Based on the briefing note, the redesign team revised the TQNE curriculum in the course of three workshops. The support team did not attend these workshops, but it provided the briefing note and suggested what decisions should be prioritized in each of these workshops. Second, we briefly describe the methodological approach chosen to evaluate the pilot courses and report on the results of this evaluation, which allow us to make conclusions about the redesign process and the scientific support.

\subsection{The Revised Curriculum}

The pivotal point of the redesign was sharpening the learning objective of the curriculum. Considering the limited scope of the study program, the redesign team decided to give preference to competences related to mastering the topic (understanding, reflecting on, and assessing sustainability-relevant issues using knowledge and theories) over competences related to designing and facilitating processes (i.e., skills needed in inter- and transdisciplinary work and in sustainability-related innovation) [47], without, however, completely excluding the latter. The following learning objective was anchored in the redesigned curriculum and operationalized in 10 learning outcomes (the focus of this paper is not on the revised curriculum but on the redesign process, so we do not go into detail about the competences informing the revised curriculum):

Students will be able to reflect critically on sustainability issues by considering and weighing different perspectives or aspects and by making use of and integrating existing knowledge. They will acquire discursive competence with regard to sustainability and be aware of problems and concerns related to sustainable development.

The redesign team reaffirmed that three of the courses should be devoted to the three scientific cultures: the social sciences, the natural sciences, and economics. The fourth course was then substantially redesigned as an integrative block course that would consolidate the competences acquired in the other three courses. The redesign thus took an integrated approach to skill acquisition, 
considering how skills should build on each other during the entire study program. With a view to providing a common focus and an integrated structure, "food and sustainability" was chosen as an exemplary topic for the next few years.

This direction was reinforced by the redesign team through another innovation, namely, the decision to start TQNE with a kick-off event in which all the main lecturers participate and contribute. This event serves (i) to communicate the basic ideas of TQNE, its learning objectives and structure, to students; (ii) to introduce the overarching topic "food and sustainability"; and (iii) to demonstrate, using the form of team teaching, how different disciplinary perspectives complement each other in tackling the topic.

The desired strengthening of active and expressive learning activities was formally anchored in the integrative block course in particular. This block course comprises interdisciplinary teamwork and is framed and accompanied by three block events. Thus, the redesigned curriculum not only takes the heterogeneity of the students into account but also uses this heterogeneity to initiate interdisciplinary learning processes. The other courses continue to be lectures with tutoring, thus giving priority to passive, receptive learning activities and placing the active, expressive learning activities in the hands of the lecturers.

\subsection{The Pilot of the Redesigned Curriculum}

The formative evaluation, which accompanied the pilot of the redesigned study program, focused on assessing the redesigned curriculum with regard to the points worked out at the beginning (diversity of topics, heterogeneity, common focus, learning activities, resonance, and number of students). That is, it was neither designed to evaluate the success and quality of the support process nor to answer research questions deduced from the scholarly debate about HESD. For this evaluation, a mixed-method approach was used. It encompassed nonparticipating observations from the kick-off and integration course, interviews with all four main lecturers, a questionnaire for all TQNE students, and a group discussion with students who completed TQNE.

Nonparticipating observations. Observations took place in the two newly conceived elements: the kick-off and the integrative block course. One person from the support team attended the course and collected data by means of semistructured observation using the main questions of whether the common focus was explicated both with regard to the topic and with regard to the overall learning objective, whether active, expressive learning activities were applied, and how active the learners were.

Semistructured interviews with the four main lecturers. The interview guidelines covered the common focus (topic related and learning-goals related), heterogeneity, learning activities, and course formats. The concrete questions focused on course planning, experiences from teaching, and evaluation based on the respondents' own criteria.

Questionnaire for all TQNE students. On one hand, students assessed the individual courses (13 to 27 students per course; response rate: 72 to 100 percent), and on the other, seven students who completed the entire program in one year evaluated TQNE as a whole. The questionnaire for the individual courses was aimed at evaluating the depth and breadth of the learning content, the common focus, interdisciplinary cooperation, and learning success (answered on a six-point scale). The questionnaire covering the entire TQNE program asked for an assessment of the structure, direction, and coherence of TQNE (answered on a six-point scale) as well as for expectations and assessment of the 10 defined learning outcomes (answered on a four-point scale).

Group discussion with students who completed TQNE. The group discussion with the seven students who completed TQNE in one year was used to qualitatively interpret and complement the results of the questionnaires.

The qualitative data were analyzed based on content; the quantitative data were evaluated using descriptive statistics. The results of the evaluation related to the common focus and learning activities are reported here. 
With regard to the common focus, the formative evaluation of the pilot courses shows that the kick-off event enabled students to start the lectures well informed. This means that this new element succeeded in conveying the new common focus. However, students still saw potential for strengthening the common focus across the three courses. One student expressed this as follows: "You noticed that it was new. It's just that when you do it for the first time, it doesn't all fit together yet, but it was fun" [translated by the authors]. In the lecturers' reports, it became clear that the common thematic focus had led them to adapt or even completely redesign their lectures. In addition, they reported that they tried to make explicit cross-references to the other lectures. The main lecturers, who participated in the redesign process, reported consistently positive experiences with the thematic focus. They thought it enabled students to go into more depth, to be more willing to discuss the topic, and to have more room for their own existing perspective or integrating point of view based on their preexistent understanding of the phenomena. One lecturer expressed this as follows: "The uniform subject is a good step. [...] If I present something from [my own disciplinary] perspective that concerns [another perspective], then I can mention it and assume that this has already been discussed [...]. That is, it gives me more room to present things from my own perspective and [...] then I have more time for integrating the perspectives" [translated by the authors]. The formative evaluation revealed that the common focus not only facilitated the development of a collaborative kick-off event and improved the lecture courses but also benefited the individual lecturers by stimulating exchange among them.

Less successful was the integrative course at achieving its goal of consolidating what was learned in the lectures. This was mainly caused by the difficulty of finding a suitable lecturer for this course (considering the requirements that teachers in interdisciplinary teaching have to meet, this is not surprising [53], and in the case of TQNE, the lecturer not only had to be qualified in interdisciplinary teaching, he/she also had to be qualified in the topic chosen for the course). Furthermore, this lecturer had to be willing to commit to the curricular requirements even though he/she had not participated in the redesign. What added to the challenge was the fact that the lecturer delivering the integrative course could not be present at the kick-off event. As a consequence, this lecturer communicated with the head of the redesign team and with members of the support team, who introduced him/her to the curricular requirements for the course, but there was no interaction with the other lecturers. It thus became apparent that it was risky and time consuming to entrust someone who had not been involved in the redesign with implementing its most significant change.

With regard to learning activities, the formative evaluation showed that the lecturers implemented various active, expressive learning activities both at the kick-off event and in their lectures, which they viewed as successful. This was confirmed by students. The lecturers said they would like to expand the use of such activities but lack the time resources to do so. One lecturer expressed this as follows: "What came up too short in my lecture were activities that helped students apply and consolidate the knowledge they had learned. [...] That's not easy because one would have to invest a lot of time" [translated by the authors]. The students would have liked to actively develop even more learning content and proposed using the tutorials more for this than only for the repetition of lecture content.

In summary, the evaluation shows that the redesign process resulted in a perceptible change for the students. Second, the entire process was, both in terms of the discussions and the changes, informed by the five points raised at its beginning; that is, the process was coherent and consistent. Third, the evaluation shows that it was at least somewhat possible to find realistic solutions to the challenges faced in TQNE and that these curricular solutions can actually guide action. One of the major changes, however, was assigned to the integrative course, and the lecturer could not fulfill what was demanded from the course (in the meantime, the lecturer has changed, and the new one is more in line with the function of the course). Finally, students indicated that the direction is right but that there is still room for improvement. 


\section{Discussion}

What lessons can be learned for scientifically supporting curricular-redesign processes? In general, first, such processes cannot take place unless all the actors responsible for and involved in delivering the curriculum are willing to change; that is, their potential resistance to change can be a limiting factor. Second, the institutional situation determines the external conditions that allow for or limit change. Third, such a process not only leads to an improved curriculum but also contributes to the professional development of academics. This section summarizes and reflects on the reported redesign process from the perspective of the lessons learned about scientifically supporting curricular-redesign processes. Our reflections here do not cover the entire redesign process but only the scientific support reported in this paper. The knowledge resulting from such reflections is, as is generally the case with action research, limited since the generated knowledge is closely linked to and so dependent on the researched situation. As a rule, action research that is tailored to a specific case has the benefit of producing knowledge that is highly relevant for the case under study, and it runs the risk of producing knowledge that can only be generalized to a limited extent. The generalizable knowledge from this case are the main demands on scientifically supporting such a redesign process. We will thus summarize these demands and then present our conclusions about the factors that were important in the redesign process.

The scientific support for the redesign process should first be understood against the background of the given situation. In this case, first, the process participants had experience-based expertise in HESD but not scholarly expertise in HESD or in curriculum development. Second, the institutional situation of the study program was not up for discussion. An examination of how the study program was structurally integrated with the various degree programs of the university showed that a change in the scope or structure of the study program would not be beneficial. A larger scope would have provided the opportunity to cover more topics but would have decreased students' ability to participate. Financial and personnel resources could have allowed for the consideration of some structural changes, but such resources were not available. Limited resources for HESD have been widely reported (e.g., [29,50]). Third, certain decisions about the redesign process shaped its scientific support: the decision to build on the experience accumulated with the practiced curriculum in the redesign led to adopting a perspective that understands curricula as action guiding and not as theoretical ideals. The redesign process therefore aimed for those involved to negotiate the new curriculum and not for experts to determine it. The criterion of success is thus whether the redesigned curriculum is implemented by those involved.

From this emerged the following demands for the scientific support of the redesign process: The support should build on the experiences of different stakeholders with the existing curriculum to ensure that decisions in the redesign process are not arbitrary. The support should enable an equal footing in the negotiation process to ensure that the redesign is not driven by individual preferences. The support should take into account theoretical and empirical insights from HESD discourse to ensure that the new curriculum reflects these insights.

The support team therefore supported the redesign process by providing aggregated "neutral" data, a basis for data interpretation, and a guide on the curricular decisions to be made. The redesign team was able to use this guidance as an orientation for the deliberative process, leading to a new TQNE supported by all. This is not only evident on paper but also in the jointly designed kick-off event, in the communication of the orientation of TQNE, and in the fact that this newly formulated orientation led the lecturers to revise or realign their courses. In the evaluation of the pilot of the redesigned TQNE, it also became clear, however, that there are aspects the main lecturers desire, such as more active and expressive learning activities, but do not have the necessary resources to implement, especially in terms of time. In summary, the findings of the evaluation and the actions that took place show that those involved in the redesign workshops were able to negotiate a curriculum supported by all. In addition, it was found that all the targeted points for the process were addressed. However, not all points were addressed to the desired extent because the resources at hand (in particular time and 
personnel) were not sufficient to tackle particular points. In other words, the process did not negate what was desired but also did not ignore the limited resources. The redesign process can therefore be said to fall in the area of conflict between the optimal curriculum - that is, the empirically and theoretically desirable curriculum - and the established paths of the existing curriculum. In this area of tension, it was possible to find a compromise for a new curriculum that was both supported by all and realistic. The support team made this area of tension explicit for the redesign team so that they could reach a consensus in this area. The area of tension was made explicit, for one, by providing experiences with the existing curriculum. For another, it was made clear by providing theoretical and practical findings about ideal and successful designs of HESD programs.

The experience in the support process thus follows findings that emphasize using existing resources as a starting point for implementing HESD (see, e.g., [50]), and it reinforces Lambrechts et al.'s [54] conclusion that it is important to make theoretical findings connectable to practice. Without this connection, the area of tension in which a consensus can be found does not become visible and cannot be explicitly discussed. This in turn points to the relevance of a common perception and framing of the problem [32]. These studies thus emphasize the importance of building a bridge between theory and practice as well as of achieving mutual understanding among those involved. Considering the demands of both action research and transdisciplinary research, it is not surprising that this easily exceeds resources in terms of actors' time and ability [30,55]. The process described in this paper shows that it is possible to outsource the research to a scientific support team. Such outsourcing requires tools for building a bridge between the real-world complexity of curriculum development and the sound evidence and reliable heuristics that enable actors to consider crucial aspects in decision-making as well as tools for building a bridge between actors' disciplinary identities and worldviews.

\section{Conclusions}

The experiences with the redesign process reported here show that the chosen approach prevents curricular changes from being made on the basis of arbitrary decisions, on individual preferences alone, or without sufficient theoretical and empirical justification. These experiences indicate key points for scientifically supporting the quality of the redesign process. The first decisive point for quality is the connection to existing experience. If data are available that provide access to existing practices, this enables the actors involved to make evidence-based decisions. The second decisive point is not to impose a specific HESD approach. Rather, providing a diversity of approaches and findings as well as practical experiences not yet reflected in HESD discourse enables those involved to make their own decisions based on current findings in HESD. The first point refers to the quality of the outcome, the redesigned curriculum; the second to the quality of the deliberative process leading to the redesigned curriculum. The third point, which proves to be decisive for quality, is the creation of a space for interdisciplinary consensus building. Such an interdisciplinary process enables all actors involved to contribute their disciplinary point of view and at the same time ensures that a common understanding of didactics and content can be developed for the study program [53].

Against this background, accompanying a process of redesign calls for those who support the process to assume the role of coaches. Scientific supporters thus have to restrain their own ideas about what decisions are right and leave room for those involved to make shared decisions, that is, they have to guide the social negotiation processes but leave the decisions up to the actors. To fulfill this role and the three quality criteria, appropriate competences are required. In particular, these competences include: mining, aggregating, and reprocessing knowledge from HESD discourse and practices; creating evidence-based databases; designing and supporting interdisciplinary processes; and finally, developing tools for enabling such a social learning process because such tools are crucial to creating the conditions for consensus building. In sum, supporting a redesign process necessitates both a firm knowledge of the relevant scholarly debate and a willingness and ability to create the necessary distance between the support team and the redesign team that is crucial for the social process of redesigning a curriculum. 
Author Contributions: Conceptualization, C.R.S., A.D.G. and P.B.-H.; methodology, C.R.S. and A.D.G.; validation, C.R.S. and A.D.G.; formal analysis, C.R.S. and A.D.G.; investigation, C.R.S., A.D.G. and P.B.-H.; resources, C.R.S. and A.D.G.; data curation, C.R.S. and A.D.G.; writing-review and editing, C.R.S., A.D.G. and P.B.-H.; project administration, C.R.S., A.D.G. and P.B.-H.; funding acquisition, P.B.-H.

Funding: This research was funded by the Swiss Academies of Arts and Sciences and the Network for transdisciplinary research (td-net), grant number A1-3. This research is part of the Sustainable Development at Universities Programme (2013-2016).

Acknowledgments: We thank the TQNE lecturers and students as well as the respondents from similar study programs for allowing us to interview them. We thank the TQNE coordinator for preparing the evaluation data and information about TQNE as well as for conducting the first interviews with the lecturers.

Conflicts of Interest: The authors declare no conflict of interest. The funders had no role in the design of the study; in the collection, analyses, or interpretation of data; in the writing of the manuscript; or in the decision to publish the results.

\section{References}

1. Lozano, R.; Lukman, R.; Lozano, F.J.; Huisingh, D.; Lambrechts, W. Declarations for sustainability in higher education: Becoming better leaders, through addressing the university system. J. Clean. Prod. 2013, 48, 10-19. [CrossRef]

2. Jones, P.; Selby, D.; Sterling, S. (Eds.) Sustainability Education: Perspectives and Practices across Higher Education; Earthscan: London, UK, 2010.

3. Barth, M.; Rieckmann, M. Academic staff development as a catalyst for curriculum change towards education for sustainable development: an output perspective. J. Clean. Prod. 2012, 26, 28-36. [CrossRef]

4. Burger, P.; Burkhardt-Holm, P.; Krysiak, F.C. Educating experts for sustainable development: The master's degree in sustainable development at the University of Basel. In Au Miroir des Disciplines. Im Spiegel der Disziplinen: Réflexions sur les pratiques d'enseignement et de recherche inter- et transdisciplinaires. Gedanken über inter- und transdisziplinäre Forschungs- und Lehrpraktiken; Darbellay, F., Paulsen, T., Eds.; Peter Lang: Bern, Switzerland, 2011; pp. 133-156.

5. Otte, I.; Prien-Ribcke, S.; Michelsen, G. Hochschulbildung auf der Höhe des 21 . Jahrhunderts. In Managementperspektiven für die Zivilgesellschaft des 21. Jahrhunderts; von Müller, C., Zinth, C.-P., Eds.; Springer: Wiesbaden, Germany, 2014; pp. 183-203. [CrossRef]

6. de Haan, G.; Kamp, G.; Lerch, A.; Martignon, L.; Müller-Christ, G.; Nutzinger, H.G.; Wütscher, F. Nachhaltigkeit und Gerechtigkeit: Grundlagen und schulpraktische Konsequenzen, 1st ed.; Springer: Berlin, Germany, 2008.

7. Svanström, M.; Lozano-García, F.J.; Rowe, D. Learning outcomes for sustainable development in higher education. Int. J. Sustain. High. Educ. 2008, 9, 339-351. [CrossRef]

8. Sipos, Y.; Battisti, B.; Grimm, K. Achieving transformative sustainability learning: engaging head, hands and heart. Int. J. Sustain. High. Educ. 2008, 9, 68-86. [CrossRef]

9. Wals, A.E.J. Mirroring, Gestaltswitching and transformative social learning: Stepping stones for developing sustainability competence. Int. J. Sustain. High. Educ. 2010, 11, 380-390. [CrossRef]

10. Wiek, A.; Withycombe, L.; Redman, C.L. Key competencies in sustainability: A reference framework for academic program development. Sustain. Sci. 2011, 6, 203-218. [CrossRef]

11. Rieckmann, M. Future-oriented higher education: Which key competencies should be fostered through university teaching and learning? Futures 2012, 44, 127-135. [CrossRef]

12. Glasser, H.; Hirsh, J. Toward the development of robust learning for sustainability core competencies. Sustain. J. Rec. 2016, 9, 121-134. [CrossRef]

13. Ploum, L.; Blok, V.; Lans, T.; Omta, O. Toward a validated competence framework for sustainable entrepreneurship. Organ. Environ. 2018, 31, 113-132. [CrossRef]

14. Barth, M.; Godemann, J.; Rieckmann, M.; Stoltenberg, U. Developing key competencies for sustainable development in higher education. Int. J. Sustain. High. Educ. 2007, 8, 416-430. [CrossRef]

15. Lourdel, N.; Gondran, N.; Laforest, V.; Debray, B.; Brodhag, C. Sustainable development cognitive map: A new method of evaluating student understanding. Int. J. Sustain. High. Educ. 2007, 8, 170-182. [CrossRef]

16. Pappas, E.; Pierrakos, O.; Nagel, R.L. Using Bloom's Taxonomy to teach sustainability in multiple contexts. J. Clean. Prod. 2013, 48, 54-64. [CrossRef] 
17. Lozano, R.; Merrill, M.; Sammalisto, K.; Ceulemans, K.; Lozano, F. Connecting competences and pedagogical approaches for sustainable development in higher education: A literature review and framework proposal. Sustainability 2017, 9, 1889. [CrossRef]

18. Cebrián, G.; Grace, M.; Humphris, D. Organisational learning towards sustainability in higher education. Sustain. Account. Manag. Policy J. 2013, 4, 285-306. [CrossRef]

19. Sammalisto, K.; Sundström, A.; Holm, T. Implementation of sustainability in universities as perceived by faculty and staff-a model from a Swedish university. J. Clean. Prod. 2015, 106, 45-54. [CrossRef]

20. Hoover, E.; Harder, M.K. What lies beneath the surface? The hidden complexities of organizational change for sustainability in higher education. J. Clean. Prod. 2015, 106, 175-188. [CrossRef]

21. Zinn, S. Nachhaltigkeit durch die partizipative Entwicklung von Kompetenzprofilen implementieren. In Nachhaltigkeit in der Lehre. Theorie und Praxis der Nachhaltigkeit; Leal Filho, W., Ed.; Springer: Berlin, Germany, 2018; pp. 127-143.

22. Corcoran, P.B.; Walker, K.E.; Wals, A.E. Case studies, make-your-case studies, and case stories: A critique of case-study methodology in sustainability in higher education. Environ. Educ. Res. 2004, 10, 7-21. [CrossRef]

23. Wals, A.E.J.; Jickling, B. Sustainability in higher education: From doublethink and newspeak to critical thinking and meaningful learning. Int. J. Sustain. High. Educ. 2002, 3, 221-232. [CrossRef]

24. Kraker, J.d. Competences and competence-based learning for sustainable development. In Crossing Boundaries: Innovative Learning for Sustainable Development in Higher Education; de Kraker, J., Lansu, A., van Dam-Mieras, R., Eds.; VAS: Frankfurt, Germany, 2007; pp. 103-114.

25. Ruesch Schweizer, C. Kompetenzen für eine Nachhaltige Entwicklung-Konzeptionelle Präzisierung der Nachhaltigkeitskompetenz über den Leistungsanspruch. In Bildung und Erziehung im Kontext globaler Transformationen; Clemens, I., Hornberg, S., Rieckmann, M., Eds.; Barbara Budrich: Berlin, Germany; Toronto, ON, Canada, 2019; pp. 111-124.

26. Barth, M.; Godemann, J. Nachhaltigkeit interdisziplinär studieren: Das Studienprogramm Nachhaltigkeit Der Uni Lüneburg (To Study Sustainable Development Interdisciplinary: Study Program Sustainability at the University of Lueneburg). ZFHE 2006, 1, 30-46. [CrossRef]

27. Hoare, A.; Cornell, S.; Bertram, C.; Gallagher, K.; Heslop, S.; Lieven, N.; MacLeod, C.; Morgan, J.; Pickering, A.; Wells, S. Teaching against the grain: Multi-disciplinary teamwork effectively delivers a successful undergraduate unit in sustainable development. Environ. Educ. Res. 2008, 14, 469-481. [CrossRef]

28. Barth, M. Many roads lead to sustainability: A process-oriented analysis of change in higher education. Int. J. Sustain. High. Educ. 2013, 14, 160-175. [CrossRef]

29. Leal Filho, W.; Pallant, E.; Enete, A.; Richter, B.; Brandli, L.L. Planning and implementing sustainability in higher education institutions: An overview of the difficulties and potentials. Int. J. Sustain. Dev. World Ecol. 2018, 25, 713-721. [CrossRef]

30. Wahr, F.; de la Harpe, B. Changing from within: An Action Research perspective for bringing about sustainability curriculum change in higher education. In Routledge Handbook of Higher Education for Sustainable Development; Barth, M., Michelsen, G., Rieckmann, M., Thomas, I., Eds.; Routledge: New York, NY, USA, 2016; pp. 161-180.

31. Bock, S.; Heiny, J. Lehrentwicklung im Zusammenspiel von Hochschuldidaktik, Lehrenden, Studierenden und Aktionsforschung. In Hochschulbildungsforschung; Jenert, T., Reinmann, G., Schmohl, T., Eds.; Springer: Wiesbaden, Germany, 2019; pp. 185-205.

32. Defila, R.; Di Giulio, A. Integrating knowledge: Challenges raised by the "Inventory of Synthesis". Futures 2015, 65, 123-135. [CrossRef]

33. Diamond, R.M. Designing and Assessing Courses and Curricula. A Practical Guide; Jossey-Bass: San Francisco, CA, USA, 2008.

34. Niethammer, C.; Koglin-Heß, I.; Digel, S.; Schrader, J. Herausforderung Curriculumentwicklung: ein konzeptioneller Ansatz zur Professionalisierung. ZFHE 2014, 9, 27-40. [CrossRef]

35. Nomme, K.; Birol, G. Course redesign: An evidence-based approach. Can. J. Scholarsh. Teach. Learn. 2014, 5, 1-26. [CrossRef]

36. Fowler, D.; Lazo, M.; Turner, J.; Hohenstein, J. Facilitating program, faculty, and student transformation: A framework for curriculum redesign. J. Transform. Learn. 2015, 3, 59-73.

37. Cornbleth, C. Curriculum in and out of Context. J. Curric. Superv. 1988, 3, 85-96. 
38. Jenert, T. Von der Curriculum zur Studienprogrammentwicklung: Argumente für eine Perspektivenerweiterung. In Pädagogische Hochschulentwicklung; Springer: Wiesbaden, Germany, 2016; pp. 119-132.

39. Salden, P.; Fischer, K.; Barnat, M. Didaktische Studiengangentwicklung: Rahmenkonzepte und Praxisbeispiel. In Pädagogische Hochschulentwicklung; Springer: Wiesbaden, Germany, 2016; pp. 133-149.

40. Wildt, J.; Wildt, B. Organisationsberatung intern-Zur partizipatorischen curricularen Entwicklung von Studiengängen an deutschen Hochschulen. GIO 2015, 46, 77-91. [CrossRef]

41. Gerholz, K.-H.; Sloane, P.F.E. Diskursive Studiengangentwicklung. In Pädagogische Hochschulentwicklung; Springer: Wiesbaden, Germany, 2016; pp. 151-170.

42. Christie, B.A.; Miller, K.K.; Cooke, R.; White, J.G. Environmental sustainability in higher education: What do academics think? Environ. Educ. Res. 2015, 21, 655-686. [CrossRef]

43. Bögeholz, S. Bewertungskompetenz für systematisches Entscheiden in komplexen Gestaltungssituationen nachhaltiger Entwicklung. In Theorien in der biologiedidaktischen Forschung; Springer: Wiesbaden, Germany, 2007; pp. 209-220.

44. Mogensen, F.; Schnack, K. The action competence approach and the 'new' discourses of education for sustainable development, competence and quality criteria. Environ. Educ. Res. 2010, 16, 59-74. [CrossRef]

45. Schneidewind, U. Transformative Literacy Gesellschaftliche Veränderungsprozesse verstehen und gestaltenTransformative Literacy. Understanding and Shaping Societal Transformations. GAIA 2013, 22, 82-86. [CrossRef]

46. Mayring, P. Qualitative Content Analysis: Theoretical Foundation, Basic Procedures and Software Solution; SSOAR: Klagenfurt, Austria, 2014. Available online: http://nbn-resolving.de/urn:nbn:de:0168-ssoar-395173 (accessed on 17 October 2019).

47. Ruesch Schweizer, C.; Di Giulio, A.; Burkhardt-Holm, P. Qualifikationsziele von Lehrangeboten zu Nachhaltigkeit. Ein Blick in die Hochschulpraxis in Deutschland und der Schweiz. In Nachhaltigkeit in der Lehre. Theorie und Praxis der Nachhaltigkeit; Leal Filho, W., Ed.; Springer: Berlin, Germany, 2018; pp. 257-276.

48. Vincent, S.; Focht, W. In search of common ground: Exploring identity and core competencies for interdisciplinary environmental programs. Environ. Pract. 2010, 12, 76-86. [CrossRef]

49. Barth, M. Implementing Sustainability in Higher Education: Learning in an Age of Transformation; Routledge: New York, NY, USA, 2015.

50. Thomas, I. Challenges for implementation of education for sustainable development in higher education institutions. In Routledge Handbook of Higher Education for Sustainable Development; Barth, M., Michelsen, G., Rieckmann, M., Thomas, I., Eds.; Routledge: New York, NY, USA, 2016; pp. 241-260.

51. Hericks, U.; Kunze, I.; Meyer, M.A. Forschung zu Didaktik und Curriculum. In Handbuch der Schulforschung; Helsper, W., Böhme, J., Eds.; VS Verlag für Sozialwissenschaften: Wiesbaden, Germany, 2004; pp. 721-752.

52. Oser, F.K.; Baeriswyl, F.J. Choreographies of teaching: Bridging instruction to learning. In Handbook of Research on Teaching; Richardson, V., Ed.; American Educational Research Association: Washington, DC, USA, 2001; pp. 1031-1065.

53. Di Giulio, A.; Defila, R. Enabling university educators to equip students with inter- and transdisciplinary competencies. Int. J. Sustain. High. Educ. 2017, 18, 630-647. [CrossRef]

54. Lambrechts, W.; Verhulst, E.; Rymenams, S. Professional development of sustainability competences in higher education: The role of empowerment. Int. J. Sustain. High. Educ. 2017, 18, 697-714. [CrossRef]

55. Seebacher, A.; Alcántara, S.; Quint, A. Der Partizipationsmythos „Partizipation bedeutet, alle immer an allem zu beteiligen“. In Transdisziplinär und transformativ Forschen: Eine Methodensammlung; Di Giulio, A., Defila, R., Eds.; Springer: Wiesbaden, Germany, 2018; pp. 101-104.

(C) 2019 by the authors. Licensee MDPI, Basel, Switzerland. This article is an open access article distributed under the terms and conditions of the Creative Commons Attribution (CC BY) license (http://creativecommons.org/licenses/by/4.0/). 